\title{
The contribution of virtual enterprises to competence-based learning: an assessment from the students' perspective: Case study
}

\author{
Massimo Bianchi ${ }^{1}$, Ana Beatriz Hernández-Lara ${ }^{2^{*}}$ and Daniele Gualdi ${ }^{3}$
}

\section{*Correspondence:}

anabeatriz.hernandez@

urv.cat

${ }^{2}$ Department of Business

Management, Rovira i Virgili

University, Av. Universitat, 1,

43204 Reus, Spain

Full list of author information

is available at the end of the article

\begin{abstract}
The use of virtual enterprises has evolved from secondary, vocational and professional
Abstract
The use of virtual enterprises has evolved from secondary, vocational and professional education to the university level, becoming in recent times a relevant experiential e-learning tool based on the simulation of the functioning of a company. The purpose of this study is to analyze the perspective of students taking part in virtual enterprises about their acquisition of generic and specific managerial skills fostered by this e-learning methodology. We analyzed data of 76 students from Faculties of Business and Economics, who had participated during the academic year 2014-2015 in a virtual company during the development of their degrees at two different Italian universities, University of Bologna and Parma. Our results show that the most valued generic skills were related to the capacity of learning and adaptation, problem solving and teamwork, while the least valued ones were related to the skills of communication and interaction with people of other countries and cultures. In the case of specific managerial skills, the most valued ones were about understanding managerial concepts and the role and functions of economic agents, and the least valued were skills related to providing managerial advice, dealing with risks and analyzing financial statements. Besides, the analyses conducted to determine the existence of a learning profile in the students reveal that the skills acquired were quite similar, not being affected by the students' gender or the economic activity developed by the virtual enterprise. This study makes a contribution in terms of the effectiveness of virtual enterprises for competence-based learning.
\end{abstract}

Keywords: Virtual enterprises, Competence-based learning, Generic competences, Specific managerial competences

\section{Background}

Numerous studies and public institutions, starting with the European Union, ${ }^{1}$ over the past few years have been highlighting the need to fill the gap between school and university education on the one side, and the changing labor market requirements on the other. Many of these requirements are a result of the need to develop appropriate competences in the work force as a consequence of the changes in the economic context, which force companies to operate in strongly competitive and unpredictable settings (Antonietti and

\footnotetext{
${ }^{1}$ See http://ec.europa.eu/europe2020/europe-2020-in-a-nutshell/flagship-initiatives/index_it.htm.
}

(c) 2015 Bianchi et al. This article is distributed under the terms of the Creative Commons Attribution 4.0 International License (http://creativecommons.org/licenses/by/4.0/), which permits unrestricted use, distribution, and reproduction in any medium, provided you give appropriate credit to the original author(s) and the source, provide a link to the Creative Commons license, and indicate if changes were made.

\section{Springer}


Tedeschi 2013). These new demands in the work force involve more complex and multidimensional competences related to entrepreneurship, innovation and knowledge management, among others (Chan et al. 2002). These competences are considered high-level characteristics encompassing personality traits and knowledge, which exert long-term effects, let to perform a more successfully job role, and have close links with organizational performance (Ettlie1997; Hayes and Wheelwright 1984; Ling 2000; Chan et al. 2002).

A more high-skill labor force will let companies to increase their added value, to be different, to attract more consumers and satisfy better their necessities, ensuring at the end the organizations' survival and growth (Autor 2011). But the challenge to obtain this skilled labor force cannot be reached with the traditional learning methods. The changes in the competence profile that students at different levels should gain also mean going beyond teaching models based on the separation between in-depth knowledge and its use as subsequent work experience, one of the concepts most often underscored in economic and education literature. For example, Visco (2014), stressing the need to invest on human resources to develop new competences for the 21st century, pointed to the need for radical changes in teaching methods and in the structure of training itself, gaining relevance the idea of new roles for instructors and teachers who now should act as moderators, facilitators and models for the students in the learning process (Hernández et al. 2010). This idea was shared by Celli (2010), who suggested that "university students should be given a vantage point to build competences which include more extensive know-how than curricular subjects", thereby anticipating during university years those "training variables which used to be specific to companies". Also, Trombetta et al. (2013a) in their research on lifelong training and innovation underline how the theory studied at university "proves to be only partially useful in terms of a student's career path". The suggestion is thus to move from a "push" training concept to a "pull" approach, which also means that "learning by doing" should go hand in hand with "learning by searching". In a nutshell, the "push" model based on learning and applying competences is incomplete, in the sense that it is necessary to use a training method where the search for knowledge is fostered through problem-solving using new digital technologies and a learning method which is largely based on the Web, more specifically, on shared platforms to disseminate knowledge and skills. According to Jonassen (1994), to build this kind of learning environment it is essential to emphasize the construction of knowledge rather than its reproduction, offering learning environments based on the real-world and case histories, as opposed to predetermined instructive sequences; this means encouraging an open-source construction of knowledge by working together.

However, although the relevance of the competence-based learning is out of debate, the academic literature on this topic is not clear about how to foster and how to assess the acquisition of proper competences' levels, and which should be the most appropriate indicators to use for guaranteeing that the competence profile acquired by students in the learning process is the most adequate for their professional development (Fitó-Bertrán et al. 2015). This gap justifies the necessity to go more in depth about how to define the competence profile of students in different disciplines, classifying these skills, and analyzing different educational situation and students' types to identify which teaching methods are the most adequate (Fitó-Bertrán et al. 2014). 
We are interested in studying one of the teaching methods based on learning by doing and how it applies the basics of constructivist thinking, along the lines proposed by Jonassen, namely the virtual enterprise (Gualdi 2001; Gualdi and Melagranati 2015). A virtual enterprise is the reproduction in a learning environment of the way of working within a real company, with students having their own position as part of the organization structure and managing all the operations involved in the virtual trading of goods and services included in the relevant network. The goal is to teach about the company, facilitating proactive learning by applying the theoretical knowledge acquired during university lectures, as well as to develop, through this practical exercise, new competences and new knowhow (Gualdi and Melagranati 2015). Setting up a virtual enterprise is just as easy as the goals, which it intends to achieve, are complex, starting from the skills required on the part of each student. Generally speaking its structure includes the main offices that make up medium-sized enterprises:

- commercial office,

- administrative office,

- HR office.

This is the basic organization structure, which can be adjusted to any situation depending on the work to be done and on the educational aims. In many virtual enterprises, for example, there is a Consulting office, whose goal is to provide services to other companies (with regard to accounting, finance, marketing or labor). This makes it possible for students to make available the specific skills that they have acquired during their studies.

The purpose of the paper is to analyze practice management in a virtual setting and to verify the competences acquired through a practice firm exercise. Specifically, we are interested in analyzing the perspective of students taking part in virtual enterprises about their acquisition of generic and specific managerial skills fostered by this e-learning methodology. To do so, we considered two samples of students participating in two virtual enterprises in the Business Schools of Bologna and Parma University.

The paper consists of five sections. The first of these is a theoretical background description, before moving on to analyzing the research carried out on a group of 76 students from Simulimpresa courses.

\section{Theoretical background}

The virtual enterprise, to function, requires a technologically advanced environment, which should include:

- a Web portal,

- the use of advanced management software for the company's IT system,

- networking with other virtual enterprises,

- open-source platforms to share and exchange information and experiences, using virtual reality tools.

The network to which a virtual enterprise belongs (the largest one worldwide is EuropenPen International), generally speaking, is managed through national Centres, which make 
available a working platform on the web. ${ }^{2}$ This makes it possible to access essential services for the practice firm: databases, the provision of services such as home banking, on-line purchases and selling transactions between enterprises and operators which are created on purpose from the virtual headquarters. The latter can be official bodies (the IRS, social security agencies, etc.), and clients or suppliers not present on the virtual marketplace. The working portal, as well as including advanced management software, allows the virtual enterprise to work almost exclusively inside a digital environment, with particular emphasis on the use of virtual reality. The appropriate management software is the IT tool that makes it possible to implement the whole IT system in a company, which can be then used for general accounting, management control or data processing (most notably financial statements), as well as making it possible for each office within the company to access all relevant information for statistical reporting purposes. The company's IT system is therefore the core of corporate management, which includes all programming tools, such as the business plan and the budget for a specific financial period with all its different sections, to implement an on-going monitoring and reporting process, which is essential for the purpose of assessing the company's performance at any given time. From a training perspective, managing the IT system is a practical exercise which enables students to enhance computer skills and to get an overview of company management as a whole, through a careful assessment of the consistency of operations carried out by all the offices, to detect possible mistakes and decide then on corrections to be made. In this respect the approach can be described as "pull-driven" because knowledge is a result of issues, which have to be dealt with and resolved on each occasion.

This learning model based on learning by doing, which is created through the virtual enterprise, can fully express its potential if it is set within digital environments where it is possible to share and exchange information, or facilitate relationships. This is why open-source platforms are used to share learning materials, courses, information and experience in the area of education.

These open-source platforms are based on connecting, teaming, networking and sharing (Trombetta et al. 2013b). Open-source platforms provide digital communication media such as conference calls, working teams and co-working networks, where expert support is provided with regard to the various topics in hand. The goal is to create a learning environment where students are able to exchange ideas with a view to solving problems, increasing their knowledge and competences, as well as working toward ongoing innovation. All this can be achieved in a virtual enterprise because the educational setting for the whole activity is purpose-made for open-source platforms and to receive more feedback from the latter to enhance the learning environment. Experience in this regard has shown that it is indeed possible to interact effectively, especially in respect of e-learning and supporting the establishment of start-up companies in different countries using virtual environments such as Second Life or other virtual reality applications (Tampieri 2009; Tampieri 2012). From an educational perspective, virtual reality offers a student in a virtual enterprise the possibility of developing new digital know-how, to extend relations using direct methods, to organize work forums on specific topics in a virtual classroom, for the purpose of "building on shared knowledge to the advantage of individuals", as well as to disseminate competences (Trombetta et al. 2013a). The result

\footnotetext{
${ }^{2}$ http://www.simulimpresa.com.
} 
is that the active role of the student as part of the learning path is highlighted because there are more sources of knowledge available which can be applied to the study environment created through a virtual enterprise.

However, despite all the benefits described above on the learning environment that virtual enterprises bring up for students, more empirical studies supported with substantial research are needed to concrete the learning outcomes, in terms of competences, acquired by students (Feinstein and Cannon 2002). The purpose of this work is to contribute in this regard trying to shed some light on the effectiveness of virtual enterprises in terms of these learning outcomes.

An analysis of previous research that measures the effectiveness of e-learning methodologies shows the flaws of these assessments that most of the times are not systematic and are based on the benefits of these methodologies, mixing within this term, a wide range of concepts that are not always the same (Fitó-Bertrán et al. 2014, 2015). Therefore, it is quite frequent that this research assesses the effectiveness and usefulness of e-learning methodologies considering different aspects separately, and without a solid justification for their election. Most of the times, these aspects are characteristics of the methodology, which are derived from the fact of being based on ICT. For example, the benefits considered can be based in the reduction of limitations due to time or space restrictions, the autonomy gained by students in their learning process, the possibility of being more active in the construction of their learning, the immediate feedback received, the practice in an on-the-job situation, effects on their motivation, the possibility to avoid risks of real decisions and the apprehension of failures or reprisal (Fu et al. 2009; Gilgeous and D'Cruz 1996; Zantow et al. 2005).

Nevertheless, these benefits related to e-leaning methodologies, and to virtual enterprises among them, do not refer directly to the competences acquired by students while using them, considering competences as the underlying characteristics of a person related to the good or excellence performance at work (González and Wagenaar 2003). In addition, previous research that consider these competences in the evaluation of e-learning methodologies normally mixes them with the characteristics, not competences, explained formerly; and frequently only considers some of them, not applying a rigorous process of selection, a systematic framework or a solid classification of competences to better understand the real contribution of these methodologies in the students' learning process (Fitó-Bertrán et al. 2014; 2015). Finally, previous research has focused in some kind of generic competences, such as teamwork, decision-making, problem solving and knowledge management, but has neglected others, normally more specific ones and those that imply particular knowledge and roles in different thematic areas, like accounting, finance and strategic management, in the case of virtual enterprises.

All these gaps justify the purpose of the present research, which consists of analyzing, from the point of view of students, the contribution of virtual enterprises to their learning process, in terms of the acquisition of generic and specific managerial competences.

By doing this, the purpose is to respond to two research questions. First, what are the most and least relevant generic and specific managerial competences fostered by the virtual enterprise methodology from the students' perspective? Second, is there a common learning profile in all the students? For this second objective, we made comparisons in terms of gender and the economic activity developed by the virtual enterprise to look for more robust results. 


\section{Methods}

\section{Data collection}

This study was conducted using data of 76 Italian students divided into two groups. Both of these comprised students at the University of Bologna-Forlì School of Economics, Management and Statistics; and University of Parma-Economics Department, who participated in two different virtual enterprises during the academic year 2014-2015. Both groups of students were studying for their first degree and were enrolled in the second or third year. The students from Forlì managed the virtual enterprise "Perting srl", whose core business was ICT (selling of telephones, computers or tablets and accessories). The same type of coursework was done by students from Parma during the first semester, through the virtual enterprise "Bec soc. coop". In the second semester, however, Bec changed its core business and moved to the food and beverage industry.

The Business Schools in Forlì and Parma are the only two universities in Italy that have introduced the virtual enterprise teaching method a long time ago. A brief experience was led by the University of Torino from 2006 to 2009. The Business School in Forlì was the first Italian university School to introduce the virtual enterprise course in 2001; followed by University of Parma in 2006. Also, recently the virtual enterprise called "Perting srl" at the Forlì School of Economics, Management and Statistics (University of Bologna), has been testing several exchange methods for open-source platforms. The Resint project ${ }^{3}$ led to establishing relationships, exchanging information and sharing experience with virtual enterprises at foreign universities through conference calls, the Second Life virtual reality and shared Web channels. Several experiences have shown that, at Simulimpresa, the use of virtual reality is especially widespread (Bianchi and Tampieri 2013; Bianchi et al. 2014) because it allows for learning outcome improvements.

The course structure is similar in terms of setting up and student involvement. Generally speaking, normally there are no more than 30 students in each group and the number of hours per course ranges between 40 and 50 . The virtual enterprise course is addressed to all students, regardless of the degree specialization they are studying for. Participants in Simulimpresa come from marketing, finance, economics and corporate management, business and non-profit organization courses. In this way, students can apply the knowledge that they have acquired during their academic studies to business practice, and at the same time they familiarize themselves with new environments through job rotation between offices, which is guaranteed by the virtual enterprise system.

\section{The questionnaire}

Data for this research were collected through a questionnaire. Three parts constituted this questionnaire. The first two parts were about competences, and the last part included questions on characteristics and the students' academic profile.

The questions related to competences were elaborated using those included in the Tuning Project. ${ }^{4}$ This project started in 2000 to link the political objectives of the Bologna process and afterward the Lisbon strategy to the higher educational sector. One of the results of this project was the elaboration of a list of competences, classified into

\footnotetext{
${ }^{3}$ RESINT Project Collaborative Reformation of Curricula on Resilience Management with Intellingent Systems in Open Source and Augmented Reality.

${ }^{4}$ http://www.unideusto.org/tuningeu.
} 
generic and specific ones, described as a dynamic combination of knowledge, understanding, skills and abilities, which educational programs seek to foster to develop a professional profile in students.

A focus group was constituted with six students who were participating in one of the virtual enterprises of this study, to obtain the students' opinion about the appropriateness of the questionnaire to capture their learning process as participants of a virtual enterprise. Their comments and suggestions were considered to improve and change some of the questions, especially the ones related to specific managerial competences. These students were eliminated of our sample.

Also, two expert professors in this learning methodology assessed the questionnaire to improve its reliability and guarantee its suitability and convenience to capture the students' perception on the utility of the virtual enterprise.

In the final version of the questionnaire, the part dedicated to generic competences included 30 items. The second part, on specific managerial competences, was composed by 21 items. All the items in these two parts used a 5-point Likert scale (where 1 means "Strongly disagree" and 5 means "Strongly agree"). The whole list of competences, both generic and specific managerial ones, can be seen in the tables included in this study in the "Results". The last part of the questionnaire, on the characteristics and academic profile of the students, included eight questions: the economic activity of the virtual enterprise in which they were participating, their university, age, gender, their degree, the name of their previous degree in the case they had previous university studies, and their opinion about the education received at university and the employment potential of their degree.

\section{Results}

All statistical analyses were carried out using R, version 3.1.1 (R Core Team 2014). Table 1 shows frequencies in the characteristics and the students' academic profile.

As Table 1 points out, our sample shows a balance in terms of gender, with equilibrium in the percentage of men and women participating in the virtual enterprises. Also, the proportion of students who participated in virtual companies in the food and beverage sector and in the ICT sector was similar. Students of Business and Economics composed $100 \%$ of the sample. Finally, the data show the good opinion that students have on the employment potential of their degree $(80.26 \%$ of the students valued this potential as good or very good), and the quality of the formation received at the university level (67.11\% of the students valued this quality as much or very much).

Given the characteristics of the sample, we considered it appropriate to distinguish the perception of students about the contribution of the virtual enterprise to foster competences comparing men and women, on the one hand, and in terms of the economic activity developed by the virtual enterprise, on the other hand.

Tables 2 and 3 show descriptive statistics and analyses of variance to check for differences between these groups of students. We computed the Shapiro-Wilk normality test and performed qqplots to determine the normality of the data. As a result we reject the hypothesis of normality, so we used non-parametric tests to determine the significance in the comparison of the mean values between the independent groups of students compared. 
Table 1 Frequencies in the characteristics and the students' academic profile

\begin{tabular}{lc}
\hline Characteristics of the students & Percentage \\
\hline Gender & 51.32 \\
Women & 48.68 \\
Men & \\
Economic activity of the virtual enterprise & 48.28 \\
Food and beverage & 51.72 \\
ICT & \\
University & 71.05 \\
University of Parma & 28.95 \\
University of Bologna (Forli) & \\
Degree & 100 \\
Business and Economics & \\
Graduated & 7.89 \\
Already graduated & 92.11 \\
First degree & \\
Quality of the university education & 1.32 \\
Very little & 2.63 \\
Little & 28.95 \\
Some & 51.32 \\
Much & 15.79 \\
Very much & \\
Employment potential of their degree & 2.63 \\
Poor & \\
Fair & \\
Good & \\
Very good & 65.79 \\
\hline
\end{tabular}

Table 2 shows the analyses conducted on generic skills. The column of total mean values shows in italics the generic competences with highest values, bigger than four points, which are the capacity to learn, capacity to adapt to new situations, problem solving and teamwork. The least valued generic competences, with values below 3.5, are in bold italic font and refer to skills related to communication, and interaction with people of other countries and cultures, such as the knowledge of a foreign language, the ability to communicate with non-experts in the field, the ability to work in an international context and to understand cultures of other countries.

The analyses conducted to compare the mean values of the generic skills considering men, on the one hand, and women, on the other, reveal that there are very few differences in the assessment of this kind of competences fostered by the virtual enterprise from the point of view of the students. Significant differences were only observed in the case of creativity and the ability to communicate with non-experts in the field. In both cases, the values given by men to these two generic competences were bigger than the values given by women.

The comparison in terms of the activity developed by the virtual company reveals also similar conclusions. Almost none significant differences were observed in this comparison. With the only exception of information management skills, which were best valued by the group in the ICT sector. 


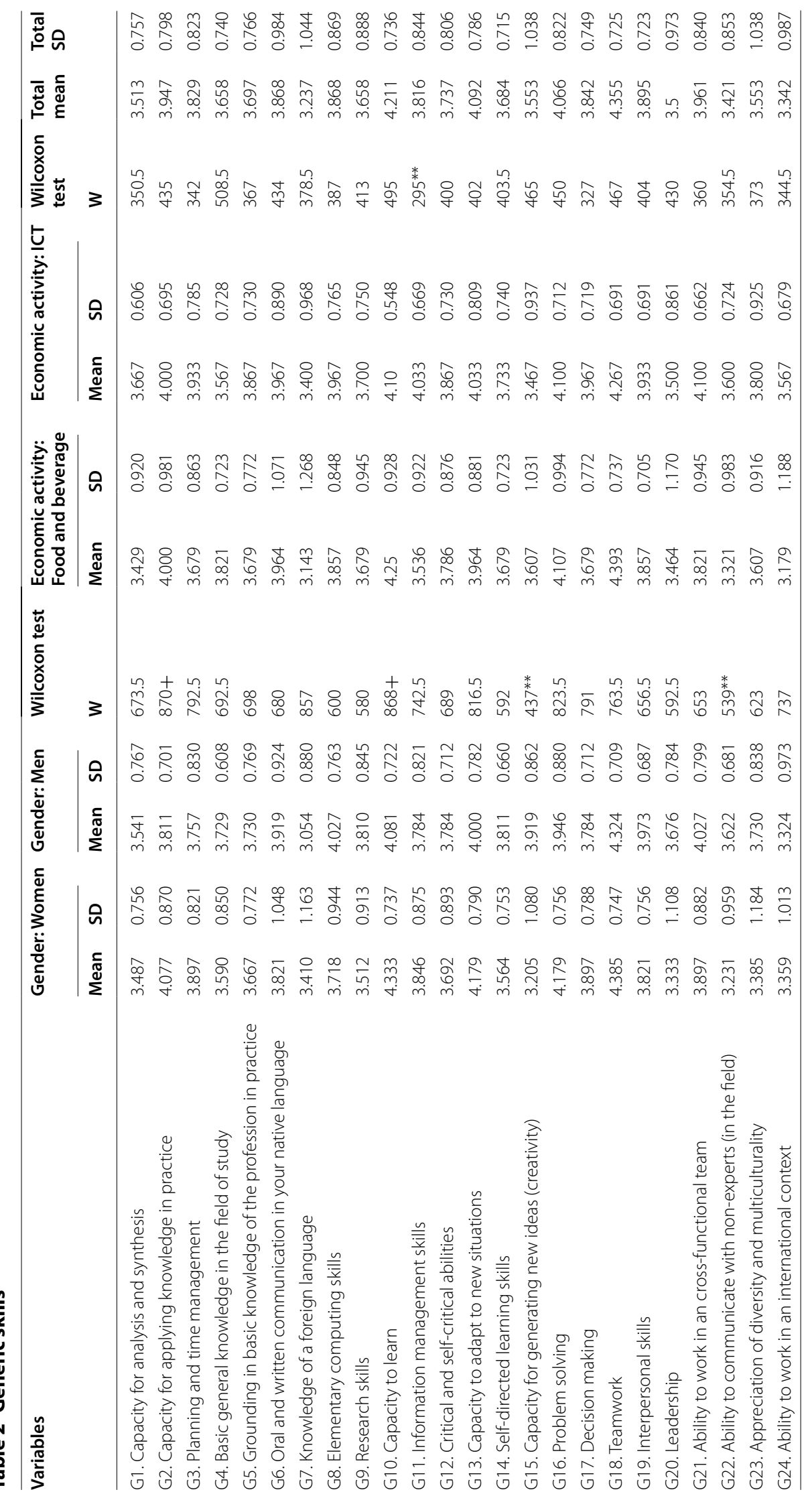




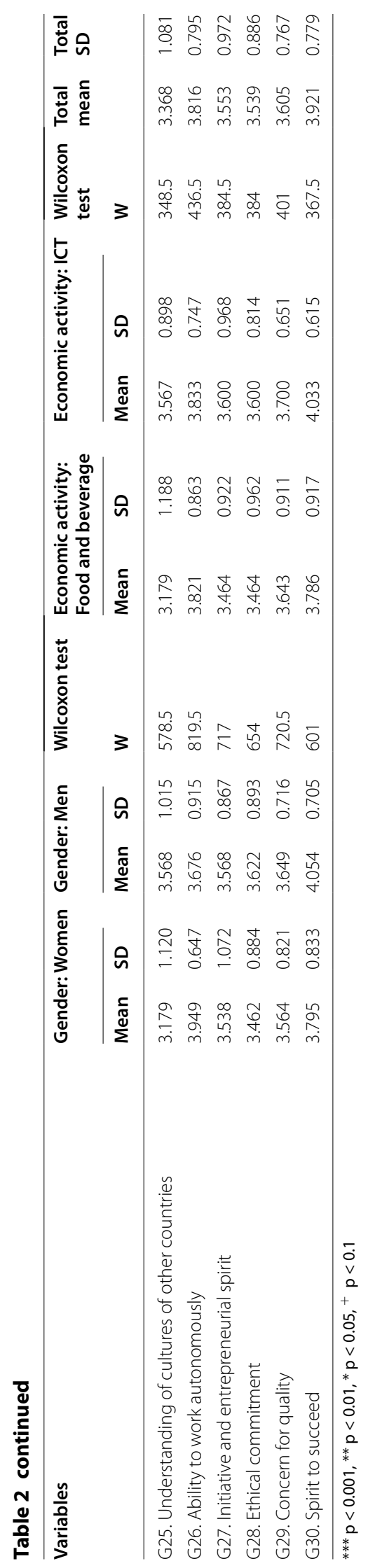




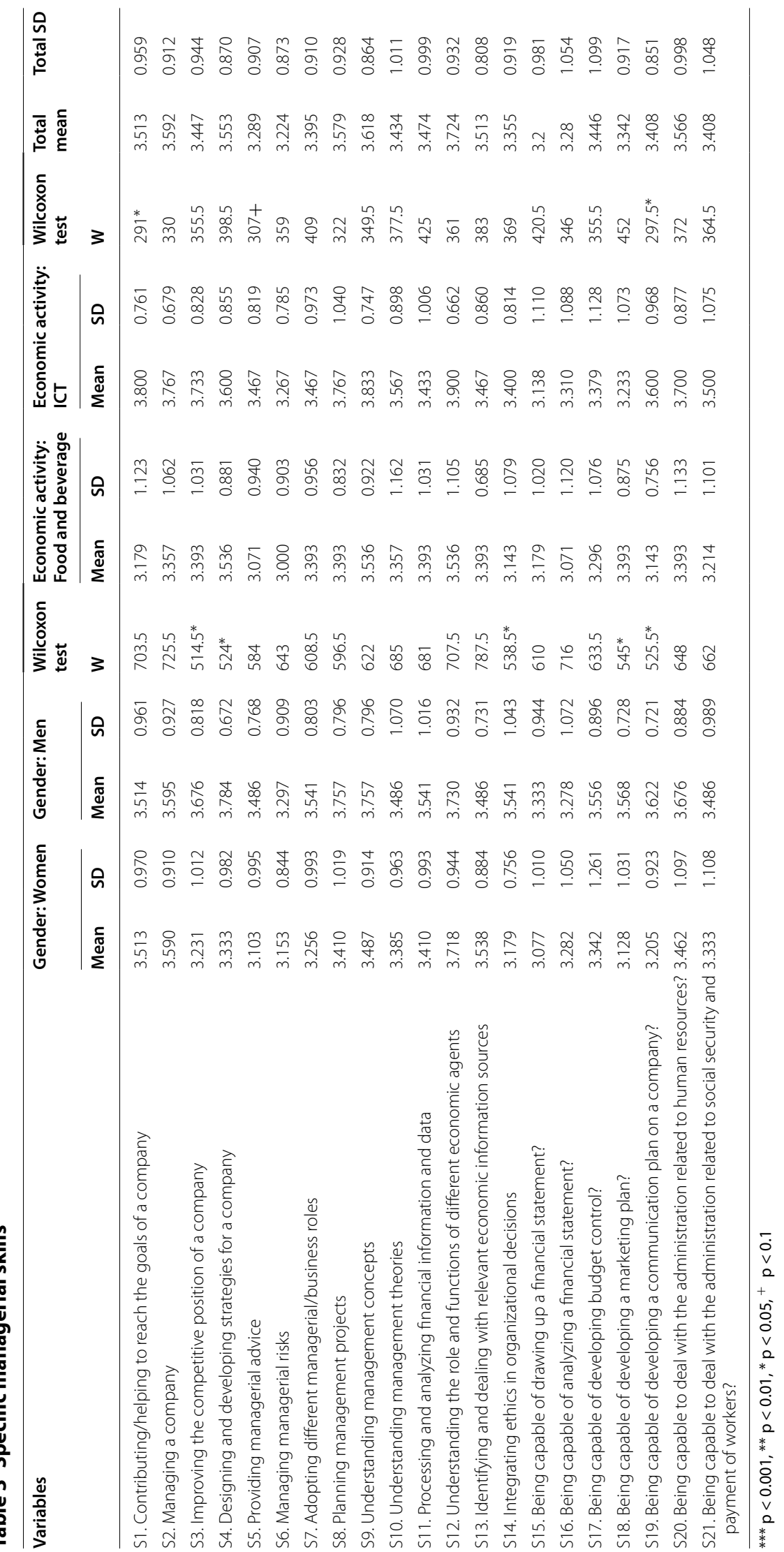


Table 3 shows the analyses made with specific managerial skills. Again, the column of total mean values allows us to get some conclusions. First, it can be observed that, in general, the students valued better generic skills than specific managerial skills. In this case, the highest values (in italics) do not arrive to four points in any case, and refer to skills related to understand the role of different economic agents and management concepts. On the other hand, the lowest values (below 3.3 and shown in bold italics) are referred to the knowledge on financial statements, providing managerial advice and managing managerial risks.

The analyses to compare the mean values of the specific managerial skills considering men and women show more differences than in the case of generic skills. To sum up, 5 out of 21 specific competences were valued differently by men and women. These competences were related to the communication and marketing plan of a company, ethics, developing strategies and improving the competitive position of a company. Men valued better all these competences.

The comparison of specific skills in terms of the activity developed by the virtual company reveals also similar conclusions. Almost none significant differences were observed in this comparison. With the only exception of skills related to reach the goals of a company and developing a communication plan, most valued by the students in the ICT sector.

We also conducted principal components analyses to visualize the behavior of competences in the groups of students. Figures 1 and 2 show these analyses for the most and least valued competences, allowing us to compare the behavior of these competences when we compare in terms of gender (Fig. 1) and in terms of the economic activity of the virtual enterprise (Fig. 2). The two main principal components explained $50.62 \%$ in data variance. From both analyses, it was obtained that in the first principal component, which capture $37.41 \%$ of data variance, the highest variability depends on generic and

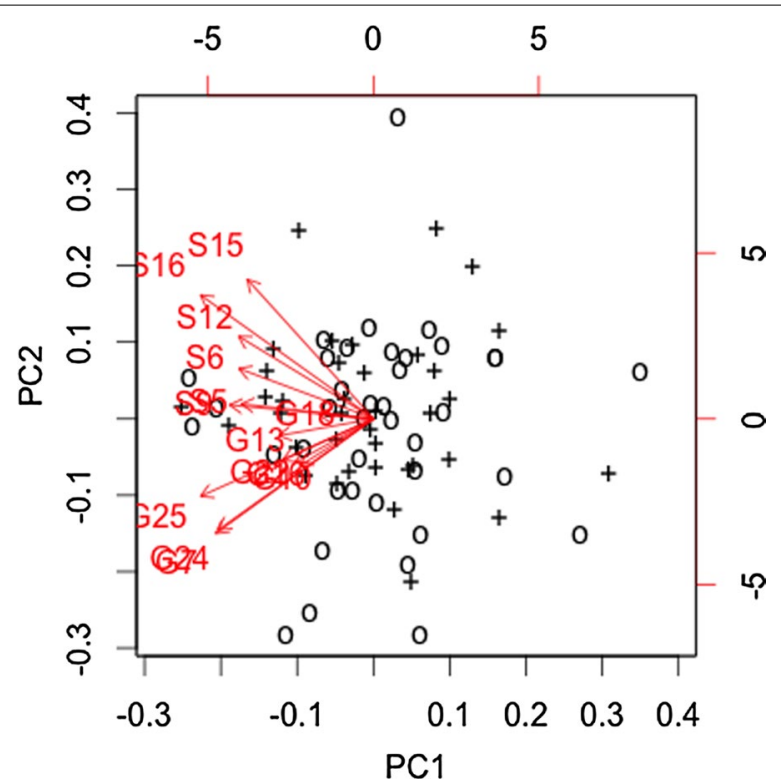

Fig. 1 Principal component analysis in terms of gender. Plus symbol: Male, Circle symbol: Female 


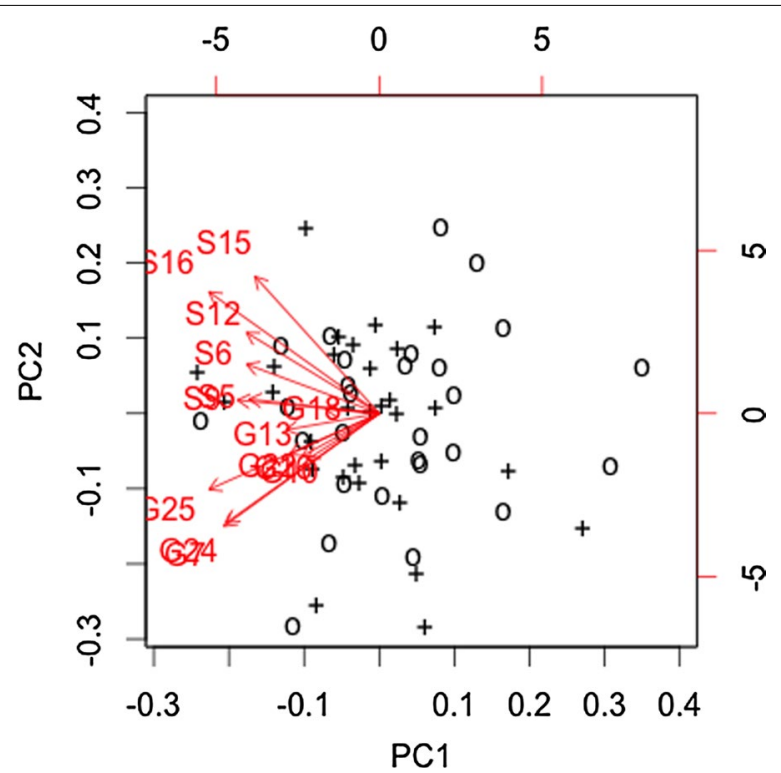

Fig. 2 Principal component analysis in terms of economic activity of the virtual enterprise. Plus symbo/ ICT, Circle symbol Food and Beverage

specific competences with the lowest values, such as the knowledge of foreign languages, analyzing financial statements and the understanding of cultures of other countries. All the competences, both generic and specific ones, covariate in a similar way. Regarding the second principal component, which explains $13.21 \%$ in data variance, the highest variability is influenced also by the same competences, but in this case, generic skills covariate the same between them but opposed to specific managerial skills that also covariate the same between them.

We could also conclude that the behavior of women and men regarding the generic and specific managerial skills most and least valued is very similar, as Fig. 1 shows; and the same occurs when the comparison is made with students participating in virtual companies dedicated to different economic activities, as it is shown in Fig. 2.

\section{Discussion and conclusions}

The purpose of this study was twofold. On the one hand, we aim to determine what are the most and least relevant competences fostered by the virtual enterprise methodology, considering different types of skills, generic and specific managerial ones. On the other hand, we seek to determine also if some relevant differences could be perceived in the competence profile of different kind of students using this e-learning method, comparing in terms of gender and in terms of the economic activity of the virtual enterprise.

The results obtained confirm that generic skills were best valued than specific managerial ones in general terms. The most relevant generic competences for students were the capacity to learn, capacity to adapt to new situations, problem solving and teamwork. These findings agree with those obtained by previous research on the effectiveness of e-learning methodologies that highlight the positive effects of these methodologies in fostering these kinds of generic skills in the students (Fu et al. 2009; Zantow et al. 2005). In the case of specific managerial ones, the most valued were related 
to the understanding of the role of different economic agents and management concepts. Despite previous research on the contribution of e-learning on specific managerial competences is quite scarce, the results of this work were also quite similar to those obtained by previous research on the effectiveness of other e-learning methodologies to foster specific competences (Fitó-Bertrán et al. 2014, 2015), which underlines the similar effects of different e-learning methodologies that are based on the same principles of active and experiential learning. The least valued competences were referred to the knowledge on financial statements, providing managerial advice and managing managerial risks, communication, and interaction with people of other countries and cultures, such as the knowledge of a foreign language, the ability to communicate with non-experts in the field, the ability to work in an international context and to understand cultures of other countries.

We also conducted some comparisons to determine if there was a consistent competence profile in different kind of students in order of gaining robustness in our results. The findings confirm that this profile was quite consistent, at least, in the students considered in our sample. The competence profile was quite similar when comparing men and women, and also when comparing students participating in virtual enterprises dedicated to different economic activities. But, the significant differences found in the level of acquisition of some competences were most numerous in the case of specific managerial competences than in the case of generic ones. It means that the students' opinion on the utility of virtual enterprises to foster competences shows a higher consensus in the case of generic skills than in the case of specific ones, where the opinions were a little bit more heterogeneous. Also, the principal components' analyses underline the different opinion of students when comparing generic and specific competences being more relevant for them the contribution of virtual enterprises to obtain the generic ones.

We think that the results obtained in this study are relevant to contribute to the academic literature on the effectiveness of virtual enterprises and other forms of e-learning, and also for professionals in the education field who need more information about the real utility of this kind of educational methodology to foster students' competences. This work has relevant implications for the theoretical basis exposed. On one hand, we have concluded the relevance of virtual enterprises to foster generic skills, and to obtain similar effects in the competence profile of students than other e-learning methodologies based on simulations. On the other hand, regarding specific managerial skills, our results confirm that more work is necessary to make the students understand and value the links between theoretical knowledge and experiential practice in the virtual enterprise. It is a responsibility up to instructors or professors using this methodology, to take profit of all its potentialities. Finally, these conclusions have been obtained considering a complete and systematic set of competences, and not just some of them separately. However, some important limitations can also be highlighted. First, the limited number of students makes difficult to generalize the results, so more data would be necessary to arrive to stronger conclusions. Second, it would be relevant to consider other students' profiles in different countries or cultural contexts, and make comparisons among them to gain a better validation of the results. Also, to include other perceptions, not only the students' opinion but also the points of view of instructors would help to acquire a better knowledge on the utility and efficacy of virtual enterprises. It would be interesting 
to consider not just perceptions, but also learning results and marks of the students extracted from the evaluation process developed by the instructors, to gain a whole idea about the effectiveness of this learning methodology. Finally, the comparison with other e-learning methodologies, like business games, would be appropriate to determine the contribution of these tools to a new learning model. All these ideas constitute relevant research lines to be developed in the future.

Authors' contributions

$M B$ has been involved in critically revising the content of the paper until the final version submitted to the journal. $\mathrm{ABHL}$ contributed in the conception and design of the study, the collection of data, carried out the statistical analysis and the interpretation of results. DG also participated in the data collection and design of the study; he was also responsible of conducting the different groups of students who participated in the learning experience explained in this study. All authors conceived the study, and participated actively in the drafts and approval of the final version of the manuscript. All authors read and approved the final manuscript.

\section{Authors' information}

All authors are academics involved in the use of virtual enterprises and other forms of related e-learning methodologies. All of them have a long experience in the use of this learning methodology, used in different context, academic levels and profile of students. MB from his position in Bologna University-Faculty of Economics Forlì has coordinated different projects on lifelong learning, simulated enterprise and intelligent systems in open source and augmented reality, among others. ABHL through her work in different universities in Spain has been also involved in different research project related to the effectiveness of business games and other forms of e-leaning methodologies in the students' learning experiences. DG is responsible of the development of Simulimpresa, in the context of business simulation, in the Universities of Parma and Bologna-Faculty of Economics Forli.

\section{Author details}

${ }^{1}$ Department of Management, Faculty of Economics Forli, University of Bologna, Bologna, Italy. ${ }^{2}$ Department of Business Management, Rovira i Virgili University, Av. Universitat, 1, 43204 Reus, Spain. ${ }^{3}$ Department of Economics, University of Parma, Parma, Italy.

\section{Acknowledgements}

The authors would like to thank the contributions, suggestions and improvements suggested by the two experts who collaborate in the revision of the questionnaire as the main tool to obtain the students' perception on the effectiveness of virtual enterprises. The authors also acknowledge that this research has been developed without any financial support or fund.

\section{Competing interests}

The authors declares that they have no competing interests.

Received: 6 June 2015 Accepted: 19 November 2015

Published online: 02 December 2015

\section{References}

Antonietti A, Tedeschi G (2013) Cavalcare le onde dell'innovazione: L'Innovazione come arma competitiva. Harvard Business Rev Suppl 12:6-10

Autor D (2011) The polarization of job opportunities in the US labor market: implications for employment and earnings. Commun Invest 23:11-41

Bianchi M, Tampieri L (2013) Simulated management in the start up of new public organizations. US China J 10:475-487 Bianchi M, Gualdi D, Tampieri L (2014) The laboratory for enterprise simulation in Forlì and the performance of Perting Ltd. 2001-2012. In: Bianchi M, Baseska M, Ngo Mai S, Tampieri L, Verges J (ed) Beyond the horizon of tempus projects. Theory and practice of project management. Società Editrice II Ponte Vecchio, Cesena. pp 235-241

Celli PL (2010) Generazione tradita. Mondadori, Milano

Chan KF, Man TY, Lau T (2002) The competitiveness of small and medium enterprises: a conceptualization with focus on entrepreneurial competencies. J Bus Ventur 17:123-142

Core Team R (2014) R: a language and environment for statistical computing. R Foundation for Statistical Computing, Vienna

Ettlie JE (1997) Integrated design and new product success. J Operat Manage 15:33-55

Feinstein AH, Cannon HM (2002) Constructs of simulation evaluation. Simul Gaming 33:425-440

Fitó-Bertrán A, Hernández-Lara AB, Serradell-López E (2014) Comparing student competences in a face-to-face and online business game. Comput Hum Behav 30:452-459

Fitó-Bertrán A, Hernández-Lara AB, Serradell-López E (2015) The effect of competences on learning results: an educational experience with a business simulator. Comput Hum Behav 51:910-914

Fu FL, Su RC, Yu SC (2009) EGameFlow: a scale to measure learners' enjoyment of e-learning games. Comput Educ 52:101-112

Gilgeous V, D'Cruz M (1996) A study of business and management games. Manage Develop Rev 9:32-39 
González J, Wagenaar R (2003) Tuning educational structures in Europe. Informe final—Proyecto piloto, fase 1. Universidad de Deusto, Bilbao

Gualdi D (2001) L'Impresa Simulata. Paramond, Milano

Gualdi D, Melagranati F (2015) Metodologie innovative nell'accounting education. La simulazione d'impresa. Indagine sulle motivazioni e aspettative degli studenti universitari di Forli e Parma. Quaderni DEM 4:1-25

Hayes RH, Wheelwright SC (1984) Restoring our Competitive Edge. John Wiley and Sons, New York

Hernández AB, Gorjup MT, Cascón R (2010) The role of the instructor in business games: a comparison of business games and online instruction. Int J Training Develop 14:169-179

Jonassen DH (1994) Thinking technology, toward a constructivist design model. Educ Technol 34:34-37

Ling XL (2000) An analysis of sources of competitiveness and performance of Chinese manufacturers. Int J Operat Product Manag 20:299-315

Tampieri L (2009) Simulazione in second life e business virtuale nello start up d'impresa del sistema moda. CLUEB, Bologna

Tampieri L (2012) Second life as educational space for the simulation of enterprises' start up and for managerial culture development. In: Bates-Brkljac Nada (ed) Virtual reality. Nova Science Publisher, New York

Trombetta S, Galli F, Dellasanta F (2013a) Formazione continua e innovazione. L'Innovazione come arma competitiva. Harvard Business Rev Suppl 12:16-23

Trombetta S, Russo R, Chiadò C (2013b) Piattaforme collaborative come leva di crescita. L'Innovazione come arma competitiva. Harvard Business Rev Suppl 12:24-29

Visco I (2014) Investire in conoscenza. II Mulino, Bologna

Zantow K, Knowlton D, Sharp DC (2005) More than fun and games: reconsidering the virtues of strategic management simulations. Acad Manage Learn Educ 4:451-458

\section{Submit your manuscript to a SpringerOpen ${ }^{\circ}$ journal and benefit from:}

- Convenient online submission

- Rigorous peer review

- Immediate publication on acceptance

- Open access: articles freely available online

- High visibility within the field

- Retaining the copyright to your article

Submit your next manuscript at $\mathbf{s p r i n g e r o p e n . c o m ~}$ 